\title{
Young people, mental illness and stigmatisation
}

\author{
Susan Bailey
}

In a recent review of the literature, Hayward \& Bright (1997) offer four possible answers to the question of "What is the root cause of an unfavourable view of "mental illness"?" First, dangerousness: people fear the mentally ill because they believe them to be prone to violence. Second, attribution of responsibility: sufferers of mental/behavioural problems are seen as more responsible for their condition. implying a belief that the mentally ill 'choose' to behave as they do. Third, conditions perceived as being chronic, difficult to treat and having a poor prognosis are more stigmatised, and fourth, the cause for stigma lies in the disruption of normal social interactions based on social role.

The World Psychiatric Association has recently initiated the development of a new worldwide educational programme on schizophrenia. The main objective is to enhance awareness of the public health importance of schizophrenia and in particular, to reduce stigma and discrimination linked to it (Sartorius, 1997). The World Mental Day Campaign 1997, had as one of its two main aims to "reduce the fear, misunderstanding and stigma, surrounding mental health problems". The Health Education Authority in the summary of findings from a national survey, Mental Health Awareness in Young People (October 1996). concluded that young people at all ages could provide a description for the terms mental health and mental illness. Mental health was described as something positive whereas perceptions of mental illness were largely negative. Language used to answer "what it means to be mentally ill" was negative in tone, indicating mental deficit, disability associated with the brain. Terms like 'sick', 'disorder' and 'ill' were used. The younger respondents were significantly more likely to associate mental illness with physical illness or physical disabilities than the older respondents. In children, negative attitudes have been seen to persist over nearly a decade (Weiss, 1986, 1994). Medical students share these prejudices to some degree but those students who reject the stereotypes are more likely to choose psychiatry as a career. The more students know about psychopathology, the less likely they are to stigmatise (Byrne, 1997).
For the past 10 years the Royal College of Psychiatrists has held a Christmas Lecture for Young People. In 1996, following Dr Michael Shooter's delivery of a thought-provoking and well received address, "Is it Dangerous to be Different?" (13 December 1996), to 200 school children (age range 11-17), 106 children completed a questionnaire asking basic questions of their understanding of and attitudes towards the mentally ill, their own concerns and their own views of appropriate intervention and help for those experiencing mental health problems.

\section{Findings}

"What names have you heard someone with mental illness being called?"

The responses were diverse but focused on a number of sub-categories including references to mental state, stereotyped behaviours, level of intelligence and medical terminology.

In total, 106 respondents were able to recall a mean of five names they had heard.

Some individuals incorporated phrases as opposed to single names. All of the phrases followed the same theme, i.e. that there was something "missing" in an individual with mental illness - "One pearl short of a choker". "One slice short of a loaf."

Table 1. What names have you heard someone with a mental illness being called?

\begin{tabular}{ll}
\hline Names heard & $\boldsymbol{n}(\%)$ \\
\hline Lunatic & $36(8.57)$ \\
Nutter & $31(7.38)$ \\
Mental & $43(10.23)$ \\
Psychopath & $72(17.14)$ \\
Retarded & $80(19.04)$ \\
Demented & $15(3.57)$ \\
Unstable & $12(2.85)$ \\
Crazy & $42(10.00)$ \\
Spastic & $61(14.52)$ \\
Peculiar & $28(6.66)$ \\
\hline
\end{tabular}


"Can anyone have mental illness?"

This question could technically only produce three responses yes, no or don't know: yes, 98.11\%; no, $1.89 \%$; don't know, $0 \%$.

The young people offered a number of diverse comments highlighting the belief that mental illness was hereditary - "Mostly when it runs through the family", "Can inherit it from their parent."

Others offered comments highlighting the belief that mental illness onset occurred at birth: - "People can be born with mental illness", "Yes, if you are deformed when you are born."

For the individuals who proffered a 'no' response - "No - developed over a process and because it may be the environment", "No - it can develop or be genetic." Perhaps one of the most illuminating comments in answer to this particular question had to be; "Yes, from the Queen to a vagrant."

\section{"What causes mental illness?"}

The responses were again diverse but focused on a number of sub-categories including references to relationship problems, physical trauma, environment and psychological problems. In total, 106 respondents were able to provide an average (mean) of three causes of mental illness.

Some individuals examined causes in a wider context and commented:

"If you have suffered a lot during an experience and have no other way of coping with the problem."

"Not sure, but maybe its when a person is so distressed from something in their past, and it builds up as they do not release their anger/upset."

"Severe life experiences which affect the person and their lifestyle - they can't cope with the situation, i.e. being raped or witnessing a murder."

"There is no single identified cause."

"The way you've been brought up."

Table 2. What causes mental illness?

\begin{tabular}{ll}
\hline Classification of response & $n(\%)$ \\
\hline Family/relationship problems & $10(9.90)$ \\
Depression & $20(19.80)$ \\
Stress & $41(40.59)$ \\
Drink/drugs & $10(9.90)$ \\
Organic/physical illness & $19(18.81)$ \\
Death/loss & $14(13.86)$ \\
Bad childhood/bullying/abuse & $26(25.74)$ \\
Insecurity/isolation & $7(6.93)$ \\
Accident & $17(16.83)$ \\
Money/job loss & $9(8.91)$ \\
General problems & $13(12.87)$ \\
Environment & $10(9.90)$ \\
Genetics & $27(26.73)$ \\
Many other factors & $4(3.96)$ \\
\hline
\end{tabular}

"Anything that is important to you that may upset you if it goes wrong."

"Anything that goes wrong, e.g. business, something they blame themselves for."

"What happens to people with mental illness?" The responses were again diverse. A number of sub-categories were evident pertaining to the behaviour of the individual who demonstrated mental illness, the responses of the general public and the variety of interventions available.

A number of individuals commented on the failure of both society and the welfare agencies to intervene:

"Some just roam the streets."

"They sometimes get treated but not many due to lack of money."

"Often snubbed by society and forced to live hidden away from society."

"Some fail to have their illness recognised at all."

"They [patients] are hidden away or their problem is ignored."

"Looked at as less equal."

"Hopefully most are cared for in hospital or at home. Sadly some commit suicide."

Table 3. What happens to people with mental illness?

\begin{tabular}{lc}
\hline & $n(\%)$ \\
\hline Behaviour of individual & \\
Withdrawn & $9(5.14)$ \\
Lose control & $12(6.86)$ \\
Violent & $4(2.29)$ \\
Lose memory & $3(1.71)$ \\
Suicide & $1(0.57)$ \\
Confused & $10(5.71)$ \\
Lack communication & $2(1.14)$ \\
Hallucinations & $2(1.14)$ \\
Psychosis & $2(1.14)$ \\
Institutionalised & $3(1.71)$ \\
Responses of members of public & \\
Indlviduals are scrutinised & $1(0.57)$ \\
Neglected & $9(5.41)$ \\
Discriminated against & $7(4.00)$ \\
Homeless & $3(1.71)$ \\
Lose privacy & $1(0.57)$ \\
Interventions & \\
Mental hospital & $41(23.43)$ \\
Treatment & $6(3.43)$ \\
Counselling & $5(2.86)$ \\
Nursing/special homes & $14(8.00)$ \\
Cared for/home care & $4(2.29)$ \\
See psychiatrist & $8(4.57)$ \\
Community care & $6(3.43)$ \\
Care & $7(4.00)$ \\
Doctor & $4(2.29)$ \\
Medication & $8(4.57)$ \\
Therapy & $2(1.14)$ \\
Hospice & $1(0.57)$ \\
\hline
\end{tabular}


Table 4. Where do you think people with mental illness should be treated?

\begin{tabular}{lc}
\hline & $n(\%)$ \\
\hline Special homes & $23(16.43)$ \\
Hospital & $64(45.71)$ \\
At home & $33(23.57)$ \\
Clinic & $6(4.29)$ \\
Care in the community & $8(5.71)$ \\
Special unit & $5(3.57)$ \\
General practitioner & $1(0.71)$ \\
\hline
\end{tabular}

"Where do you think people with mental illness should be treated?"

The responses here were far less ambiguous.

Some individuals incorporated a general comment rather than stipulating a specific place for intervention:

"In a different building to where everyone else is."

"They [patients] should be treated in a place that is high security and a place where they are comfortable and safe."

"They [patients] should not be locked away from society and should receive treatment in a stable environment and a caring atmosphere."

"People are being put into the community without the care that they need."

"They [patients] can't help being ill, so I don't think they should go to hospital."

"Somewhere quiet and private so that people who don't understand can't harm them [patients]."

\section{"Who do you think should treat them?"}

The responses were diverse in terms of which professional should have responsibility for treatment programmes. Equally diverse was the range of alternative carers considered appropriate to treat individuals with mental illness.

Some individuals incorporated a comment as opposed to a single term in an effort to highlight

Table 5. Who do you think should treat them?

\begin{tabular}{lc}
\hline & $n(\%)$ \\
\hline $\begin{array}{l}\text { Professional } \\
\text { Doctor }\end{array}$ & $44(22.22)$ \\
Psychiatrist & $38(19.19)$ \\
Specially trained person & $29(14.65)$ \\
Nurse & $20(10.10)$ \\
Counsellors & $10(5.05)$ \\
Psychologist & $9(4.55)$ \\
Care worker/befriender & $6(3.03)$ \\
Alternative carers & \\
Family & $2(13.64)$ \\
Friends & $8(4.57)$ \\
Ex-patients & $4(2.02)$ \\
Volunteers & $3(1.52)$ \\
\hline
\end{tabular}

the importance of both alternative care provision and the importance of continuity of care.

"People [professionals] should train members of the family to help the patient who will then feel more at home."

"They [patients] should not just be treated by people who have studied mental illness."

"Support from the community should help improve the patients' condition."

"The patient's family [should treat them] which should be reinforced by social workers."

"They [patients] should also have contact with everyone else in order to ensure that people learn to accept them as part of their lives/society."

\section{Discussion}

The Young People demonstrated a wide range of responses, level of understanding and acceptance of the mentally ill. Page \& Day (1990) comment that the mentally ill are victimised by the generalised effect of a pejorative label and also by the strong possibility of experiencing behavioural discrimination in particular situations. They conclude that the use of a special lexicon based on the metaphor of mental illness does not appear to have altered some basic components of human nature, nor society's basic moral position toward its stigmatised minorities. Overall the young people who completed the current questionnaire looked to adults to find constructive solutions but also for themselves to be part of this process.

Mental illness impacts on the lives of many young people. In any one year one in five young people may experience psychological problems which are severe enough to require some form of professional help. Emotional and behavioural disorders leading to significant impairment occur in around $5 \%$ of this population and severe mental disorders are less common but none the less occurring in up to $1 \%$ of the child population (further details available from the author upon request). Young people who may be developing mental illness need (together with their families) early intervention from mental health professionals without the additional fear of stigmatisation.

Early education about mental health and the facts of mental illness is critical if attitudes are to alter. The challenge is how we as a profession join the educationalists and the voluntary organisations to provide a programme of education and understanding. The Refrewshire Experience (Refrewshire Association for Mental Health Education, 1996) strongly suggests that education aimed at secondary school pupils, should be what they actually want to hear, not what the educator thinks they want to hear, or what the educator thinks they should hear. The best educators would be those who have directly 
experienced illness and who are at ease in a variety of group settings. Materials appropriate for classroom use need to be developed and education should contain a strong element of promoting emotional well-being.

\section{References}

BYRNE. P. (1997) Psychiatric stigma the past, passing and to come. Journal of Royal Society of Medicine, 90, 618-621.

HAYWARD, P. \& BRIGHT, J. A. (1997) Stigma and Mental

Illness. A Review and Critique. Journal of Mental Health. 6. 345-354.

PAGE. S. \& DAY, P. (1990) In acceptance of 'the mentally ill. Canadian society, reality and illusion. Canadian Journal of Community Mental Health, 9, 151-161.
SARTORIUS, N. (1997) Fighting schizophrenia and its stigma. A new World Psychiatric Association educational programme. British Journal of Psychiatry. 170, 297.

R.A.M.H. Education (1996) The Renfrewshire Experience. School Mental Health Promotion. Paisley: Refrewshire Association for Mental Health.

WEISS, M. (1986) Children's attitudes towards the mentally ill - a developmental analysis. Psychological Reports. 58. 11-20.

- (1994) Children's attitudes toward the mentally ill, an eight year longitudinal follow-up. Psychological Reports. 74. 51-56.

Susan Bailey, Consultant Adolescent Forensic Psychiatrist, Adolescent Forensic Service, Mental Health Services of Salford, Burg New Road, Prestwich, Manchester M25 3BL

\section{Antisocial Personality Disorder: An Epidemiological Perspective}

by Paul Moran

In 1980, the controversial diagnostic category of 'antisocial personality disorder' was introduced in psychiatry. This book provides a comprehensive review of antisocial personality disorder from an epidemiological point of view. It opens with a discussion of the central problems associated with assessing and classifying abnormal personality and then focuses more specifically on antisocial personality disorder with chapters on: distribution, natural history, early risk factors, associated conditions, burden and needs assessment. It will be a valuable source of reference for all who are interested in the disorder, whether from a clinical, management or research perspective.

January 1999, s12.50, 144pp, ISBN 1901242242

Available from Book Sales, Royal College of Psychiatrists, 17 Belgrave Square, London SW1X 8PG Tel +44 (0) 1712352351 (ertension 146), Fax +44 (0) 1712451231

http://www.rcpsych.ac.uk 